\title{
Effect of Standard No. 2800 Rules for Moment Resisting Frames on the Elastic and Inelastic Behavior of Dual Steel Systems
}

\author{
Hedayat Veladi \\ Department of Structural Engineering \\ Faculty of Civil Engineering \\ University of Tabriz \\ Tabriz, Iran
}

\author{
Hamideh Najafi \\ Department of Structural Engineering \\ Faculty of Civil Engineering \\ University of Tabriz \\ Tabriz, Iran
}

\begin{abstract}
According to most valid Design Codes including the Iranian Seismic Design Code (Standard No. 2800), moment resisting frames in dual systems must have the ability of resisting the $25 \%$ of the total lateral load of the dual system independently. This study is conducted to investigate the implementation of this rule for dual steel structures with two types of steel braced frame. Also, its effect on the strength of the structure and the distribution of lateral load between the frames and the bracing system is evaluated. In order to investigate the effect of that rule, structural models with 5,10 and 15 floors are modeled. Nonlinear static analysis is employed and results are discussed. Following the Standard No. 2008 seems to increase the structure's lateral resistance and decrease the number of elements entered into the inelastic behavior stage. In general, the structure has a more desirable inelastic behavior.
\end{abstract}

Keywords-dual system; moment resisting frame; bracing system; lateral resistance; non-linear analysis

\section{INTRODUCTION}

A dual system is defined as a structure which resists horizontal loads by a combination of shear wall and rigid frames or, in the case of steel structures, by braced frames and rigid frames. Previously, in the traditional design of dual structures, it was assumed that the bracing systems resisted all lateral loads and the frames were designed considering only the gravity loads. When a dual structure is loaded laterally, the horizontal interaction is due to the different free deflection forms of the walls and frames. So, the individual distribution of lateral loading on the bracing system and the frame may be very different from the distribution of lateral loading. The affectivity of a dual structure depends on the amount of horizontal interaction, which is influenced by the relative stiffness of the bracing system and the height of the structure [1]. Recent studies show that the characteristics of the moment resisting frame in the dual system are of the most important factors affecting interaction [2]. In dual systems, the braced frame $(B F)$ is named the primary system and the moment resisting frame (MRF) is named the secondary or backup system. Actually, the MRF intends to provide a secondary supply of strength and energy dissipation for the dual system and also acts as a secondary line of defense against damage caused by severe earthquakes. Experimental studies have shown that MRFs are assumed as the first system after failing the BFs [3-4]. Researchers have proposed a variety of different methods for analyzing dual structures. Each of these methods is based on different assumptions and models. Authors in [5] presented a numerical and iterative method to analyze a dual structure. This method of converging approximations provides a solution that can be carried to any degree of refinement by increasing the number of cycles until the desired result is attained. The proposed numerical solution requires no simplifying assumptions of the structural behavior of configurations that are not checked during some steps of the analysis. In this method, analysis has been performed in two steps. In the first step, the deflected shape and amount of lateral load distributed to BF and MRF have been determined at each floor. The second step of analysis has been performed by subjecting isolated bend to the deflection pattern derived from the iteration solution for the entire structure.

Authors in [6] obtained the differential equations of a dual system with uniform stiffness along the height. They derived closed-form solutions to the lateral deformations, bending moment and shear forces for cases subjected to uniform or triangular static lateral load distributions. Authors in [7] presented an approximate method for the sway estimation of dual buildings. The results were similar to those from stiffness matrix analysis for a building uniform in height. Authors in [8] presented another concept to increase the lateral stiffness of dual tall building structures by stiffening the floor of the frame system either at the top or at an intermediately optimized level. The shear rigidity of the frame system is increased in floor level by infilling one or more bays of the frames in floor with concrete or masonry panel or adding bracing to the floor or increasing the size of the columns and girders surrounding it. This concept is simple, easy to apply and it can reduce the top deflection and increase the lateral stiffness of a dual structure by a large magnitude. Authors in [9] presented a method to derive the governing equations of the dual structure with outriggers formulated through the continuum approach. In this method, the whole structure has been idealized as a shear- 
flexural cantilever with rotational springs. The effects of shear deformation and flexural deformation of the dual system and outriggers trusses have been regarded and incorporated in the formulation of the governing equations. This method is relatively simple and efficient and provides reasonably accurate results in the early design stage of tall building structures.

Authors in [10] presented a simple analytical method based on a continuum model. This method evaluated the sway of dual building subjected to various types of lateral loads. Limited floor drifts can be controlled by this method. A stability index equation without sway terms was determined by using the developed analytical expressions. Additionally, dual structure interaction can be modeled simply and the moment at the base level can be computed. Authors in [11] studied the significance of $25 \%$ design requirement for the secondary moment frames in dual systems with consideration of current structural practice. Results of this study displayed that a secondary moment frame designed to resist less than $25 \%$ of seismic demand may be adequate for consideration as a dual system regardless of the $25 \%$ rule. Authors in [12] investigated the performance of dual structures. Their analysis indicated that adding special moment resisting frame (SMRF) to the buckling restrained braced frame (BRBF) system changes the natural period slightly and provides the optimum stiffness proportion for dual systems. Also, based on the findings of this research, it was proposed to perform nonlinear analysis for predicting deficiencies related to inherent differences of behavior of the two systems, since this deficiencies cannot be predicted and recognized in linear static analysis. Authors in [13] evaluated the stiffness limit value required for the secondary system for BRBF and SMRF dual systems. This study indicated that the suitable stiffness combination ratio is obtained when the BRBF and SMRF subsystems are $65 \%$ and $35 \%$ of the total stiffness respectively. Also, implementation of the suitable relative stiffness leads to a uniform plasticity profile in the height of structures. Since shear distribution between BF and MRF in a dual structure is important, valid codes including ASCE 7 [14] and Iranian Seismic Design Code (Standard No. 2800) [15] have specified special criteria for dual structures. According to Standard No. 2800, MRF must be able to resist at least $25 \%$ of the required lateral load independently. This study is conducted to investigate the effect of the considering lateral load bearing of MRF in the dual system. In other words, the structures with MRF resistance of $25 \%$ of lateral load independently are compared with structures without implementation of this rule. Additionally, the results are compared in elastic and inelastic behavior stages.

\section{MODELING HYPOTHESIS AND ANALYSIS}

The models used in this paper are of dual structures (steel moment resisting frame and steel bracing system) with 5, 10 and 15 floors. Each frame has three panels of which the middle panel is braced with two types of $\mathrm{X}$ and inverted $\mathrm{V}$ bracing systems. The length of each panel in frames is $5 \mathrm{~m}$ and the height of stories is $3.2 \mathrm{~m}$. Scale modeling of the 5 floor structure with $\mathrm{X}$ and inverted $\mathrm{V}$ bracing system are shown in Figure 1. Supports are fixed and BF and MRF existing in the dual system are medium ductility moment resisting frame and bracing system. Plan of structures in both main orthogonal directions is assumed symmetric, therefore models are considered 2D. According to ASCE7 [14], dead and live gravity load at stories and roof are considered as $500 \mathrm{~kg} / \mathrm{m}^{2}$ and $200 \mathrm{~kg} / \mathrm{m}^{2}$, respectively. Partition load is assumed to be 100 $\mathrm{kg} / \mathrm{m}^{2}$ which is added to the dead load of stories. The steel used is Mild Steel with yield strength of $F_{y}=2400 \mathrm{~kg} / \mathrm{m}^{2}$, ultimate strength of $F_{u}=3700 \mathrm{~kg} / \mathrm{m}^{2}$, Young's module of $E=2 \times 10^{6}$ $\mathrm{kg} / \mathrm{m}^{2}$ and Poisson's ratio of 0.3 . The seismic load was calculated by equivalent static seismic load method according to the Iranian Seismic Design Code (Standard No. 2800). Models are assumed in regions with high seismicity level with design base acceleration (A) equal to 0.35 and moderate importance with an importance factor of 1.0. It was assumed that structures are located on type 2 soil. In order to control the lateral load bearing of MRF in dual structures, in calculating of seismic load, the Building Behavior Factor $(\mathrm{R})$ was considered to be 7.0 which is the Building Behavior Factor of intermediate ductility, steel moment resisting frame and steel concentric braced frame. Frames are analyzed and designed by the Allowable Stress Design (ASD) method according to AISCASD 89 [16]. Cross section of beams, columns and braces are selected IPE, IPB and Box profiles, respectively.

\section{LATERAL LOAD BEARING OF MRF}

According to rule 1-9-4 of the Standard No. 2800, the following criteria are specified for dual structure:

a) An essentially complete space frame that provides support for gravity loads.

b) Resistance of the lateral load is provided by shear walls or braced frames and moment resisting frames. Floor shear for each group at each floor is evaluated according to their lateral stiffness.

c) Moment resisting frame shall be capable of carrying at least $25 \%$ of the design base shear, independently.

Note: when a system fails to conform to criterion (c), the system shall be classified as a building frame system.

According to the above-mentioned requirements, in order to evaluate the lateral load bearing of MRF, structures were analyzed and designed in two cases. In the first case, gravity and seismic loads were applied on MRF and BF at the same time. In other words, rule 1-9-4 was not applied (model (a)). In the second case, rule 1-9-4 was not applied (model (b)). Dual structures were modeled and analyzed in two steps. At first, elastic design and analysis were performed using ETABS2000 software and then, nonlinear static analysis was performed using the SAP2000 software. In order to control lateral load bearing of MRF, it was needed to increase and strengthen the cross section of some beams and columns; therefore assigned cross sections were bigger in the second model.

\section{MEMBER SECTIONS OF MODELS}

Tables I-VI present member sections of structures with Xbracing system for both models, (a) and (b). In case (b) some beams and columns have sections bigger than the model (a) because of the bearing of $25 \%$ of seismic loads independently by MRF. 
TABLE I. (a): MEMBERS CROSS SECTION - 5 FLOOR STRUCTURE - X BRACE

\begin{tabular}{|c|c|c|c|c|c|}
\hline Story & $\begin{array}{c}\text { Middle } \\
\text { Column }\end{array}$ & $\begin{array}{c}\text { Side } \\
\text { Column }\end{array}$ & $\begin{array}{c}\text { Middle } \\
\text { Beam }\end{array}$ & $\begin{array}{c}\text { Side } \\
\text { Beam }\end{array}$ & Brace \\
\hline 1 & IPB240 & IPB160 & IPE300 & IPE300 & BOX90X90X10 \\
\hline 2 & IPB200 & IPB160 & IPE300 & IPE300 & BOX90X90X10 \\
\hline 3 & IPB16 & IPB160 & IPE300 & IPE300 & BOX90X90X7.1 \\
\hline 4 & IPB140 & IPB140 & IPE300 & IPE300 & BOX80X80X8 \\
\hline 5 & IPB120 & IPB140 & IPE300 & IPE300 & BOX70X70X5.9 \\
\hline
\end{tabular}

TABLE II. (a): MEMBERS CROSS SECTION - 10 FLOOR STRUCTURE - X BRACE

\begin{tabular}{|c|c|c|c|c|c|}
\hline Story & $\begin{array}{c}\text { Middle } \\
\text { Column }\end{array}$ & $\begin{array}{c}\text { Side } \\
\text { Column }\end{array}$ & $\begin{array}{c}\text { Middle } \\
\text { Beam }\end{array}$ & $\begin{array}{c}\text { Side } \\
\text { Beam }\end{array}$ & Brace \\
\hline 1 & IPB550 & IPB220 & IPE300 & IPE330 & BOX100X100X14.2 \\
\hline 2 & IPB400 & IPB220 & IPE300 & IPE330 & BOX100X100X12.5 \\
\hline 3 & IPB360 & IPB200 & IPE300 & IPE330 & BOX100X100X10 \\
\hline 4 & IPB280 & IPB200 & IPE300 & IPE300 & BOX100X100X10 \\
\hline 5 & IPB260 & IPB200 & IPE270 & IPE300 & BOX100X100X7.1 \\
\hline 6 & IPB220 & IPB200 & IPE270 & IPE300 & BOX100X100X7.1 \\
\hline 7 & IPB180 & IPB180 & IPE270 & IPE300 & BOX90X90X8 \\
\hline 8 & IPB160 & IPB180 & IPE270 & IPE300 & BOX90X90X5.9 \\
\hline 9 & IPB140 & IPB140 & IPE270 & IPE300 & BOX80X80X5.4 \\
\hline 10 & IPB120 & IPB140 & IPE270 & IPE300 & BOX70X70X4.5 \\
\hline
\end{tabular}

TABLE III. (a): MEMBERS CROSS SECTION - 15 FLOOR STRUCTURE - X BRACE

\begin{tabular}{|c|c|c|c|c|c|}
\hline Story & $\begin{array}{c}\text { Middle } \\
\text { Column }\end{array}$ & $\begin{array}{c}\text { Side } \\
\text { Column }\end{array}$ & $\begin{array}{c}\text { Middle } \\
\text { Beam }\end{array}$ & $\begin{array}{c}\text { Side } \\
\text { Beam }\end{array}$ & Brace \\
\hline 1 & IPB1000 & IPB320 & IPE300 & IPE360 & BOX100X100X14.2 \\
\hline 2 & IPB900 & IPB320 & IPE300 & IPE360 & BOX100X100X14.2 \\
\hline 3 & IPB800 & IPB280 & IPE300 & IPE360 & BOX100X100X14.2 \\
\hline 4 & IPB600 & IPB260 & IPE300 & IPE360 & BOX100X100X12.5 \\
\hline 5 & IPB450 & IPB260 & IPE300 & IPE360 & BOX100X100X12.5 \\
\hline 6 & IPB400 & IPB240 & IPE300 & IPE330 & BOX100X100X10 \\
\hline 7 & IPB340 & IPB240 & IPE300 & IPE330 & BOX100X100X10 \\
\hline 8 & IPB300 & IPB240 & IPE300 & IPE330 & BOX100X100X8 \\
\hline 9 & IPB280 & IPB240 & IPE300 & IPE330 & BOX90X90X10 \\
\hline 10 & IPB240 & IPB220 & IPE300 & IPE300 & BOX90X90X8 \\
\hline 11 & IPB220 & IPB220 & IPE300 & IPE300 & BOX90X90X7.1 \\
\hline 12 & IPB200 & IPB200 & IPE300 & IPE300 & BOX90X90X5.9 \\
\hline 13 & IPB180 & IPB180 & IPE300 & IPE300 & BOX80X80X7.1 \\
\hline 14 & IPB160 & IPB160 & IPE300 & IPE300 & BOX80X80X4.5 \\
\hline 15 & IPB120 & IPB140 & IPE300 & IPE300 & BOX60X60X5 \\
\hline
\end{tabular}

TABLE IV. (b): MEMBERS CROSS SECTION - 5 FLOOR STRUCTURE - X BRACE

\begin{tabular}{|c|c|c|c|c|c|}
\hline Story & $\begin{array}{c}\text { Middle } \\
\text { Column }\end{array}$ & $\begin{array}{c}\text { Side } \\
\text { Column }\end{array}$ & $\begin{array}{c}\text { Middle } \\
\text { Beam }\end{array}$ & $\begin{array}{c}\text { Side } \\
\text { Beam }\end{array}$ & Brace \\
\hline 1 & IPB240 & IPB200 & IPE300 & IPE330 & BOX90X90X10 \\
\hline 2 & IPB200 & IPB160 & IPE300 & IPE300 & BOX90X90X10 \\
\hline 3 & IPB180 & IPB160 & IPE300 & IPE300 & BOX90X90X7.1 \\
\hline 4 & IPB160 & IPB160 & IPE300 & IPE300 & BOX80X80X8 \\
\hline 5 & IPB120 & IPB140 & IPE300 & IPE300 & BOX70X70X5.9 \\
\hline
\end{tabular}

TABLE V. (b): MEMBERS CROSS SECTION - 10 FLOOR STRUCTURE - X BRACE

\begin{tabular}{|c|c|c|c|c|c|}
\hline Story & $\begin{array}{c}\text { Middle } \\
\text { Column }\end{array}$ & $\begin{array}{c}\text { Side } \\
\text { Column }\end{array}$ & $\begin{array}{c}\text { Middle } \\
\text { Beam }\end{array}$ & $\begin{array}{c}\text { Side } \\
\text { Beam }\end{array}$ & Brace \\
\hline 1 & IPB550 & IPB240 & IPE300 & IPE330 & BOX100X100X14.2 \\
\hline 2 & IPB400 & IPB220 & IPE300 & IPE330 & BOX100X100X12.5 \\
\hline 3 & IPB360 & IPB220 & IPE300 & IPE330 & BOX100X100X10 \\
\hline 4 & IPB280 & IPB200 & IPE300 & IPE330 & BOX100X100X10 \\
\hline 5 & IPB260 & IPB200 & IPE300 & IPE330 & BOX100X100X7.1 \\
\hline 6 & IPB220 & IPB200 & IPE300 & IPE330 & BOX100X100X7.1 \\
\hline 7 & IPB180 & IPB200 & IPE300 & IPE330 & BOX90X90X8 \\
\hline 8 & IPB160 & IPB180 & IPE300 & IPE330 & BOX90X90X5.9 \\
\hline 9 & IPB140 & IPB140 & IPE300 & IPE330 & BOX80X80X5.4 \\
\hline 10 & IPB120 & IPB140 & IPE300 & IPE300 & BOX70X70X4.5 \\
\hline
\end{tabular}

TABLE VI. (b): MEMBERS CROSS SECTION - 15 FLOOR STRUCTURE - X BRACE

\begin{tabular}{|c|c|c|c|c|c|}
\hline Story & $\begin{array}{c}\text { Middle } \\
\text { Column }\end{array}$ & $\begin{array}{c}\text { Side } \\
\text { Column }\end{array}$ & $\begin{array}{c}\text { Middle } \\
\text { Beam }\end{array}$ & $\begin{array}{c}\text { Side } \\
\text { Beam }\end{array}$ & Brace \\
\hline 1 & IPB1000 & IPB320 & IPE330 & IPE360 & BOX100X100X14.2 \\
\hline 2 & IPB900 & IPB320 & IPE330 & IPE360 & BOX100X100X14.2 \\
\hline 3 & IPB800 & IPB280 & IPE330 & IPE360 & BOX100X100X14.2 \\
\hline 4 & IPB650 & IPB260 & IPE330 & IPE360 & BOX100X100X12.5 \\
\hline 5 & IPB500 & IPB260 & IPE330 & IPE360 & BOX100X100X12.5 \\
\hline 6 & IPB400 & IPB260 & IPE330 & IPE360 & BOX100X100X10 \\
\hline 7 & IPB340 & IPB240 & IPE330 & IPE360 & BOX100X100X10 \\
\hline 8 & IPB300 & IPB240 & IPE300 & IPE360 & BOX100X100X8 \\
\hline 9 & IPB280 & IPB240 & IPE300 & IPE330 & BOX90X90X10 \\
\hline 10 & IPB240 & IPB220 & IPE300 & IPE300 & BOX90X90X8 \\
\hline 11 & IPB220 & IPB220 & IPE300 & IPE300 & BOX90X90X7.1 \\
\hline 12 & IPB200 & IPB200 & IPE300 & IPE300 & BOX90X90X5.9 \\
\hline 13 & IPB180 & IPB180 & IPE300 & IPE300 & BOX80X80X7.1 \\
\hline 14 & IPB160 & IPB160 & IPE300 & IPE300 & BOX80X80X4.5 \\
\hline 15 & IPB120 & IPB140 & IPE300 & IPE300 & BOX60X60X5 \\
\hline
\end{tabular}

\section{NON-LINEAR MODELING OF STRUCTURES}

FEMA-356 [17] was used to perform the nonlinear static analysis. The designing procedure in FEMA is based on performance levels. Building performance is a combination of the performance of both structural and nonstructural components; therefore, performance levels are defined according to structural and non-structural damages. The structural performance level of building shall be selected from three discrete structural performance levels. The discrete structural performance levels are Immediate Occupancy (IO), Life safety (LS) and Collapse Prevention (CP).

IO structural performance level means the post-earthquake damage state in which only very limited structural damage has occurred. The basic vertical and lateral force resisting system retain nearly all of their pre-earthquake strength and stiffness. LS structural performance level means the post-earthquake damage state in which significant damage to the structure has occurred. Some structural elements are severely damaged but this has not resulted in large falling debris hazards. CP structural performance level means the post-earthquake damage state in which the building is on the verge of partial or total collapse. Substantial damage to the structure has occurred, potentially including significant degradation in the stiffness and strength of the lateral force resisting system and large permanent lateral deformation of the structure [17]. Criteria of performance level shall be selected in accordance with primary and secondary elements. It should be mentioned that in the considered structures, only beams, columns and braces were modeled; therefore the conducted non-linear static analysis was considered as simplified analysis and acceptance criteria were selected in accordance with primary elements. A target displacement is a characteristic displacement in the structure that serves as an estimate of the global displacement experienced by the structure. In this paper target displacement, $\delta_{t}$, at each floor level calculated according to (1) which has been provided by FEMA-356:

$$
\delta_{t}=C_{0} C_{1} C_{2} C_{3} S_{a} \frac{T_{e}^{2}}{4 \pi^{2}} g
$$

where: 
- $\mathrm{C}_{0}=$ modification factor to relate spectral displacement of an equivalent SDOF system to the roof displacement of the building MDOF system.

- $\mathrm{C}_{1}=$ modification factor to relate expected maximum inelastic displacement to displacement for the linear elastic response.

- $\mathrm{C}_{2}=$ modification factor to represent the effect of pinched hysteretic shape, stiffness degradation and strength deterioration on maximum displacement response.

- $\mathrm{C}_{3}=$ modification factor to represent increased displacement due to dynamic P- $\Delta$ effects.

- $\mathrm{S}_{\mathrm{a}}=$ response spectrum acceleration, at the effective fundamental period and damping ratio of the building.

- $\mathrm{g}=$ acceleration of gravity

- $\mathrm{T}_{\mathrm{e}}=$ effective fundamental period of the building in the direction under consideration, sec.

The multi-linear curve was used in order to simplify the behavior of members. Multi-linear curves used in SAP2000 software and FEMA-356 are shown in Figures 2 and 3. In other words, behavior diagram of "plastic force-displacement" and "plastic moment-rotation" has been defined for each degree of freedom of force or moment. It should be mentioned that the slope of strain hardening (slope from B to C) was considered $3 \%$, according to FEMA. In non-linear behavior modeling of structure, which have been provided by FEMAs-356 "Deformation Controlled Components" expected yield and ultimate strength of steel were calculated according to (2) and (3):

$$
\begin{aligned}
& F_{y e}=1.1 F_{y} \\
& F_{u e}=1.1 F_{u}
\end{aligned}
$$

where:

- $\mathrm{F}_{\mathrm{ye}}=$ expected yield strength

- $\mathrm{F}_{\mathrm{yu}}=$ expected ultimate strength

- $\mathrm{F}_{\mathrm{y}}=$ yield strength

- $\mathrm{F}_{\mathrm{u}}=$ ultimate strength

Since the connection of beams and columns is fixed and also because of that the gravity load is not much, plastic hinges have been assigned at the two ends of these members. So, plastic hinges approximately have been extended by the length equal to the depth of the member's cross section. Therefore, plastic hinges have been considered at relative distances of 0.05 and 0.95 of element lengths.

\section{RESULTS OF LINEAR STATIC ANALYSIS}

\section{A. Shear Distribution between MRF and BF}

Figures 4 and 5 show the share of $\mathrm{X}$ and inverted $\mathrm{V}$ bracing system from floor shear for both models (a) and (b) in each floor. It is observed that the share of floor shear in a bracing system generally has decreased at the model (b). It is due to strengthening MRF in model (b), that the bracing system has not changed. It is noted that, due to the increase of weight in model (b), base shear in this case is increased. At the structure with the X-bracing system, the share of MRF from the base shear, in models (a) and (b) at 5-floors structure are 9\% and $11.2 \%$, at a 10 -floors structure $21.7 \%$ and $22.2 \%$ and at a 15 floors structure are $35.8 \%$ and $36.8 \%$ respectively. Also, these values at the structure with the inverted $\mathrm{V}$ bracing system in the case of 5-floors structure are $4.5 \%$ and $5.1 \%$, at 10 -floors structure are $15.4 \%$ and $16 \%$ and at 15 -floors structure are $32.3 \%$ and $32.7 \%$, respectively. It is observed that by increasing the number of stories, the share of MRF from base and story shear has increased.

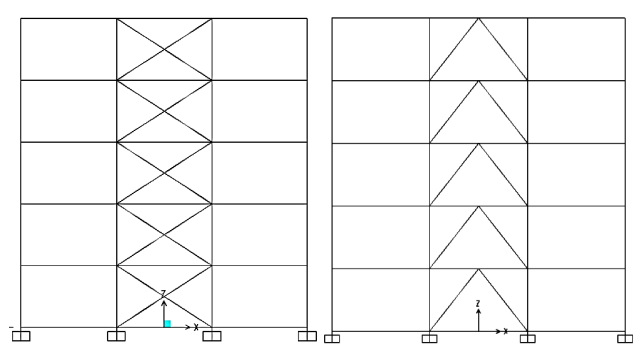

Fig. 1. Scale modeling of 5 story structure with $\mathrm{X}$ and inverted $\mathrm{V}$ bracing system.

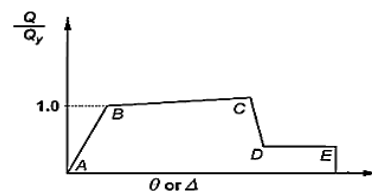

Fig. 2. FEMA Multi-linear curve

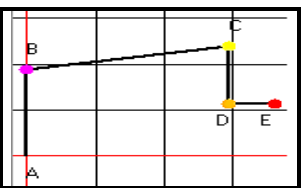

Fig. 3. SAP2000 software Multi-linear curve.

\section{B. Effect of Bracing System Type}

In Figure 6, the share of $\mathrm{X}$ and inverted $\mathrm{V}$ bracing system from the floor shear has been shown for the model (b). A structure with the $\mathrm{X}$-bracing system is called $\mathrm{X}$ and with the inverted $\mathrm{V}$ bracing system is called IN V. It was observed that in all cases an increase in the floor number leads to increase in the share of MRF from the share force, especially in higher stories. In general, the share of MRF from floor and base shear in the structure with the $\mathrm{X}$ bracing system is larger than in the structure with the inverted V bracing system. Additionally, in both structures, much of the base shear is resisted by the bracing system. 

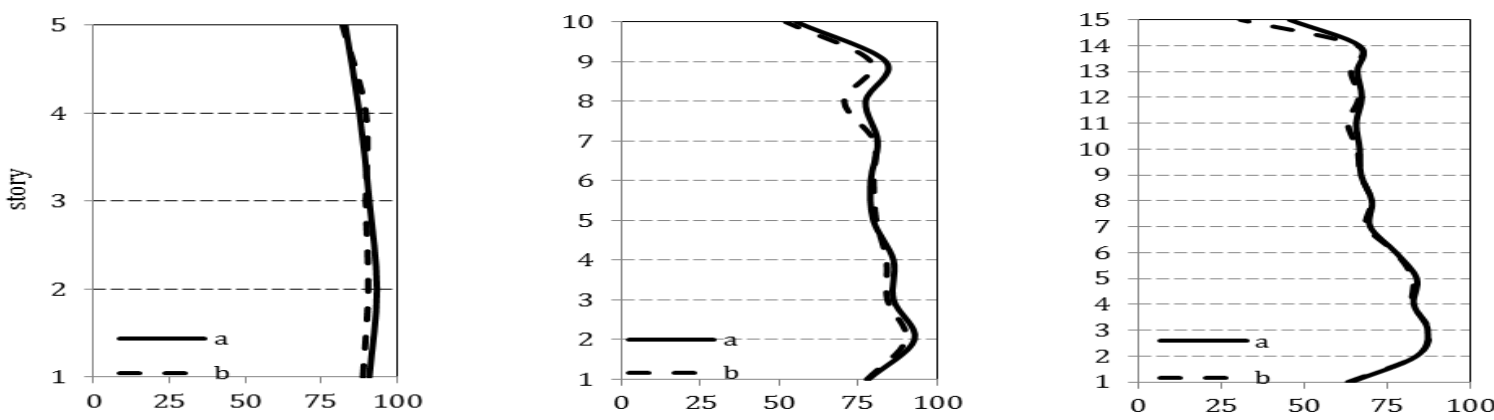

Fig. 4. Share of $\mathrm{X}$ bracing system from floor shear in linear static analysis (shear force of the bracing system to floor shear (\%)).
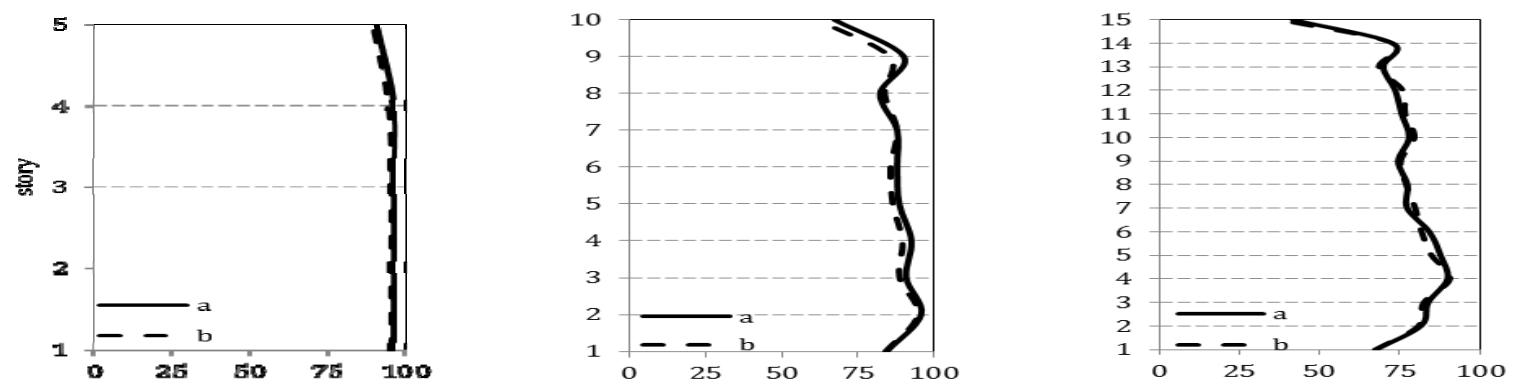

Fig. 5. Share of inverted V bracing system from floor shear in linear static analysis (shear force of the bracing system to story shear (\%)).
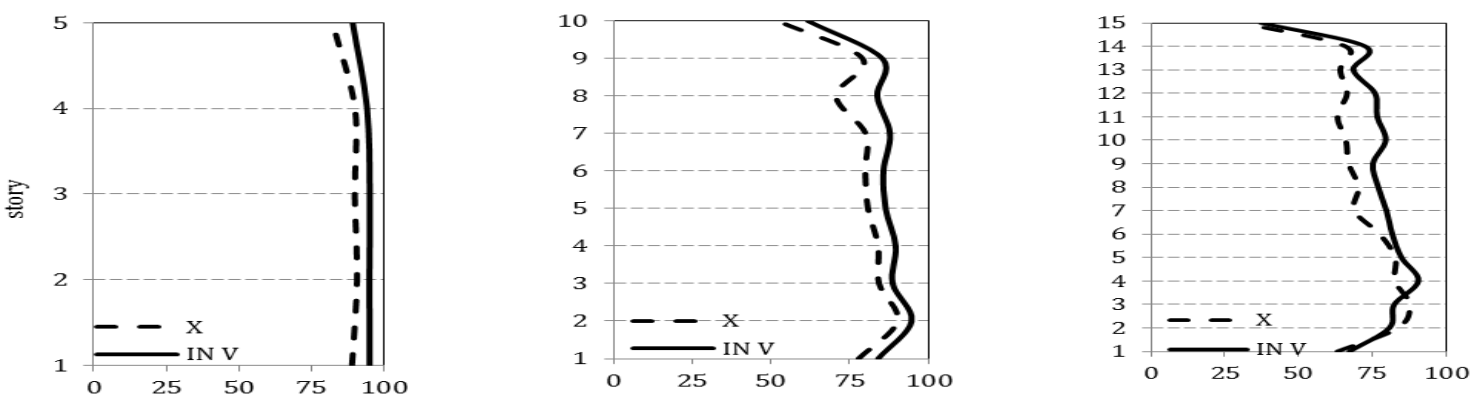

Fig. 6. Share of $\mathrm{X}$ and inverted $\mathrm{V}$ bracing system from floor shear in linear static analysis (model (b)) (shear force of the bracing system to story shear (\%)).

\section{RESULTS OF NON-LINEAR STATIC ANALYSIS}

\section{A. Pushover Curves of Structures}

According to FEMA-356 guideline in the non-linear static analysis, the seismic load was applied with two triangular and uniform lateral load patterns on structures. In all of the models, triangular lateral load pattern (appropriate with the lateral load in the linear static analysis) was the critical pattern and so it was used. The pushover curve of 5, 10 and 15 floor structures with $\mathrm{X}$ and inverted $\mathrm{V}$ bracing systems have been shown in Figures 7-12. Generally, the capacity of structure in the model (b) has been increased in comparison with model (a).

\section{B. Maximum Base Shear}

Maximum base shear of 5, 10, and 15 floor structures with two types of bracing system have been presented in Tables VII and VIII. As it is observed in the tables, generally amounts of base shear have increased in the model (b) due to the strengthening of beams and columns.

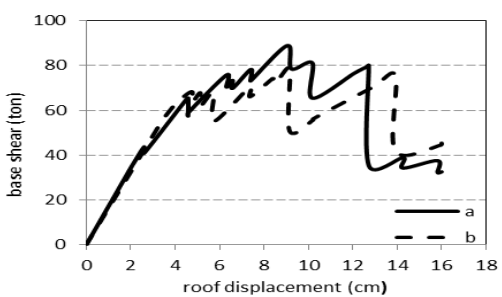

Fig. 7. Pushover curve of 5 floor structure (X brace).

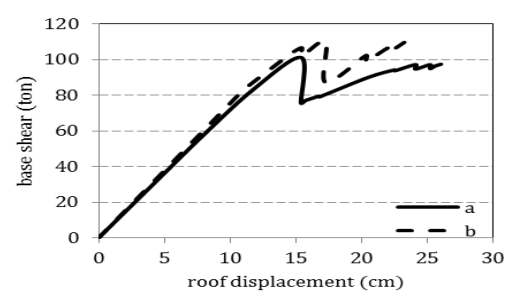

Fig. 8. Pushover curve of 10 floor structure (X brace). 


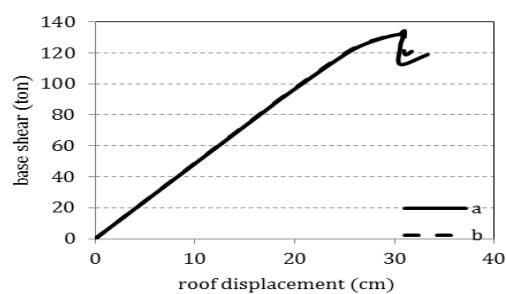

Fig. 9. Pushover curve of 15 floor structure (X brace).

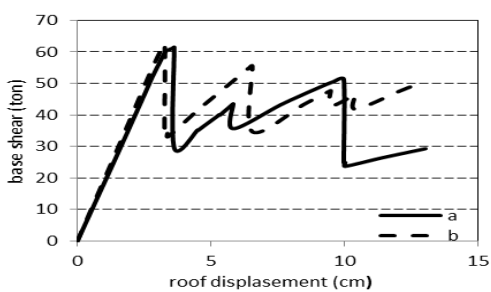

Fig. 10. Pushover curve of 5 floor structure (V brace).

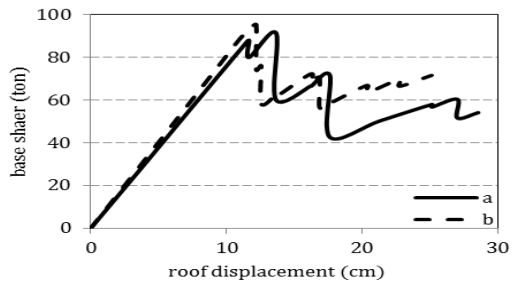

Fig. 11. Pushover curve of 10 floor model (V brace).

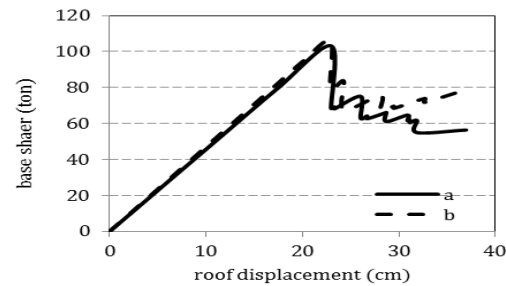

Fig. 12. Pushover curve of 15 floor model (V brace).

TABLE VII. MAXIMUM BASE SHEAR OF STRUCTURES WITH X BRACING SYSTEM

\begin{tabular}{|c|c|c|c|}
\hline \multirow{2}{*}{ floor } & \multicolumn{2}{|c|}{ Maximum base shear (ton) } & \multirow{2}{*}{$\begin{array}{c}\text { relative } \\
\text { difference b to a }\end{array}$} \\
\cline { 2 - 3 } & $\mathbf{a}$ & $\mathbf{b}$ & -11.7 \\
\hline 5 & 88.95 & 78.54 & 12.6 \\
\hline 10 & 97.38 & 109.63 & 3.2 \\
\hline 15 & 131.88 & 136.04 & \\
\hline
\end{tabular}

TABLE VIII. MAXIMUM BASE SHEAR OF STRUCTURES WITH INVERTED V BRACING SYSTEM

\begin{tabular}{|c|c|c|c|}
\hline \multirow{2}{*}{ floor } & \multicolumn{2}{|c|}{ Maximum base shear (ton) } & \multirow{2}{*}{$\begin{array}{c}\text { relative } \\
\text { difference b to a }\end{array}$} \\
\cline { 2 - 3 } & $\mathbf{a}$ & $\mathbf{b}$ & 1.2 \\
\hline 5 & 61.51 & 62.24 & 4 \\
\hline 10 & 91.43 & 95.13 & 2.7 \\
\hline 15 & 103.19 & 105.98 & \\
\hline
\end{tabular}

\section{Formation Process and Distribution of Plastic Hinges}

The formation process and the distribution of plastic hinges have an important effect in seismic design. Therefore, formation and distribution of plastic hinges were evaluated for 5, 10, and 15-floor structures for both models (a) and (b). It was observed that model (b) has fewer elements entering an inelastic behavior stage compared to model (a) and less plastic hinges formed. Also, these plastic hinges have formed in later time step. In addition, by the strengthening of the MRF in model (b), less plastic hinges have formed in beams and columns and plastic hinges mostly were formed in braces.

\section{Structural Performance Level of Models}

The number of plastic hinges at different performance levels has been summarized in Tables IX and X for both types of bracing systems. At both B to IO and IO to LS performance levels, it is observed that the number of plastic hinges for model (b) is generally lower, so it can be said that model (b) has a more desirable nonlinear behavior. It is worth noting that the reduction of hinges is larger for inverted $\mathrm{V}$ bracing systems compared to $\mathrm{X}$ bracing systems. At the LS to CP performance level, there have not been any plastic hinges in the structures with inverted $\mathrm{V}$ bracing and the structures remained at the LS performance level; whereas the number of plastic hinges has decreased and increased respectively in the 10 and 15 floor buildings of model (b) with the X bracing system. Generally, it can be concluded that model (b) has better performance level in all cases. The coordination of the performance point of structures obtained from FEMA365 and SAP2000 has been presented in Tables XI and XII.

TABLE IX. NUMBER OF PLASTIC HINGES AT DIFFERENT PERFORMANCE LEVEL (X BRACING SYSTEM)

\begin{tabular}{|c|c|c|c|c|c|c|}
\hline $\begin{array}{c}\text { Performance } \\
\text { level }\end{array}$ & \multicolumn{2}{|c|}{$\begin{array}{c}\text { 5 floor } \\
\text { structure }\end{array}$} & \multicolumn{2}{c|}{$\begin{array}{c}\text { 10 floor } \\
\text { structure }\end{array}$} & \multicolumn{2}{c|}{$\begin{array}{c}\text { 15 floor } \\
\text { structure }\end{array}$} \\
\cline { 2 - 7 } & a & b & a & b & a & b \\
\hline A to B & 58 & 60 & 108 & 119 & 178 & 174 \\
\hline B to IO & 9 & 6 & 22 & 17 & 32 & 29 \\
\hline IO to LS & 1 & 2 & 14 & 5 & 27 & 24 \\
\hline LS to CP & 0 & 0 & 3 & 2 & 2 & 7 \\
\hline CP to C & 2 & 2 & 4 & 2 & 0 & 4 \\
\hline C to D & 0 & 0 & 0 & 0 & 0 & 0 \\
\hline D to E & 10 & 10 & 9 & 15 & 1 & 2 \\
\hline
\end{tabular}

TABLE X. NUMBER OF PLASTIC HINGES AT DIFFERENT PERFORMANCE LEVELS ( INVERTED V BRACING SYSTEM)

\begin{tabular}{|c|c|c|c|c|c|c|}
\hline $\begin{array}{c}\text { Performance } \\
\text { level }\end{array}$ & \multicolumn{2}{|c|}{$\begin{array}{c}\text { 5 floor } \\
\text { structure }\end{array}$} & \multicolumn{2}{c|}{$\begin{array}{c}\text { 10 floor } \\
\text { structure }\end{array}$} & \multicolumn{2}{c|}{$\begin{array}{c}\text { 15 floor } \\
\text { structure }\end{array}$} \\
\cline { 2 - 7 } & $\mathbf{a}$ & $\mathbf{b}$ & $\mathbf{a}$ & $\mathbf{b}$ & $\mathbf{a}$ & $\mathbf{b}$ \\
\hline A to B & 70 & 76 & 146 & 149 & 208 & 232 \\
\hline B to IO & 8 & 2 & 4 & 6 & 27 & 2 \\
\hline IO to LS & 1 & 1 & 6 & 4 & 4 & 5 \\
\hline LS to CP & 0 & 0 & 0 & 0 & 0 & 0 \\
\hline CP to C & 0 & 0 & 0 & 0 & 0 & 0 \\
\hline C to D & 0 & 0 & 0 & 0 & 0 & 0 \\
\hline D to E & 1 & 1 & 2 & 1 & 1 & 1 \\
\hline
\end{tabular}




\section{E. Share of Bracing System from Shear Force in Nonlinear Static Analysis}

Shares of the bracing system from the floor shear of the structure with both types of bracing system in models (a) and (b) are shown in Figures 13 and 14. Diagrams are presented at the maximum base shear step. It is observed that in model (b) with both types of bracing system, the share of the bracing system has decreased in the 5 and 10 -floor structures but in the 15 -floor structure it has fairly increased in some floors. At the base level, the share of MRF in models (a) and (b) in the 5floor structure with the X-bracing system are $13.4 \%$ and $23.4 \%$, in the 10 -floor structure are $19.4 \%$ and $19.8 \%$ and in the 15 -floor structure are $36 \%$ and $50 \%$, respectively. Also, these values at the structure with the inverted $\mathrm{V}$ bracing system in case of the 10 -floor structure are $7.2 \%$ and $6.3 \%$, at 10 -floor structure are $18.5 \%$ and $19.5 \%$ and at 15 -floor structure are $39.7 \%$ and $40 \%$, respectively. Comparison of non-linear and linear static analysis showed some differences between the base shear resisted by MRF in the structure with two types of bracing systems in elastic and inelastic stages.
TABLE XI. THE COORDINATION OF THE PERFORMANCE POINT OF STRUCTURES AT PUSHOVER CURVE (X BRACING SYSTEM)

\begin{tabular}{|c|c|c|}
\hline floors & model & Point of (V,D) \\
\hline \multirow{2}{*}{5} & $\mathrm{a}$ & $(70,10)$ \\
\cline { 2 - 3 } & $\mathrm{b}$ & $(65.4,7)$ \\
\hline \multirow{2}{*}{10} & $\mathrm{a}$ & $(93,15)$ \\
\cline { 2 - 3 } & $\mathrm{b}$ & $(105,15)$ \\
\hline \multirow{2}{*}{15} & $\mathrm{a}$ & $(117.6,25)$ \\
\cline { 2 - 3 } & $\mathrm{b}$ & $(118.2,25)$ \\
\hline
\end{tabular}

TABLE XII. THE COORDINATION OF THE PERFORMANCE POINT OF STRUCTURES AT PUSHOVER CURVE (INVERTED V BRACING SYSTEM)

\begin{tabular}{|c|c|c|}
\hline floors & model & Point of (V,D) \\
\hline \multirow{2}{*}{5} & a & $(43,6)$ \\
\cline { 2 - 3 } & b & $(55.5,7)$ \\
\hline \multirow{2}{*}{10} & a & $(68,14)$ \\
\cline { 2 - 3 } & b & $(75.12)$ \\
\hline \multirow{2}{*}{15} & a & $(83,23)$ \\
\cline { 2 - 3 } & b & $(97,23)$ \\
\hline
\end{tabular}
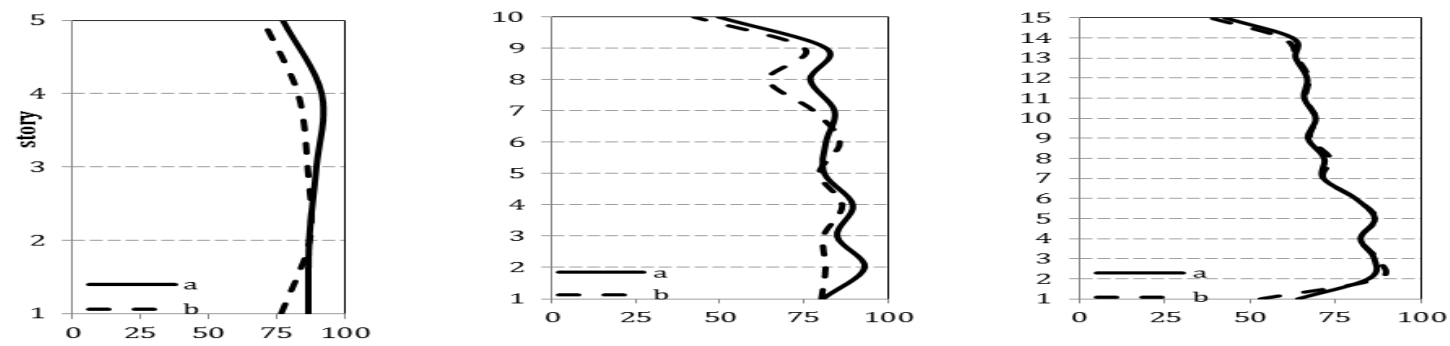

Fig. 13. Share of $\mathrm{X}$ bracing system from floor shear in nonlinear static analysis (Shear force of the bracing system to floor shear (\%)).
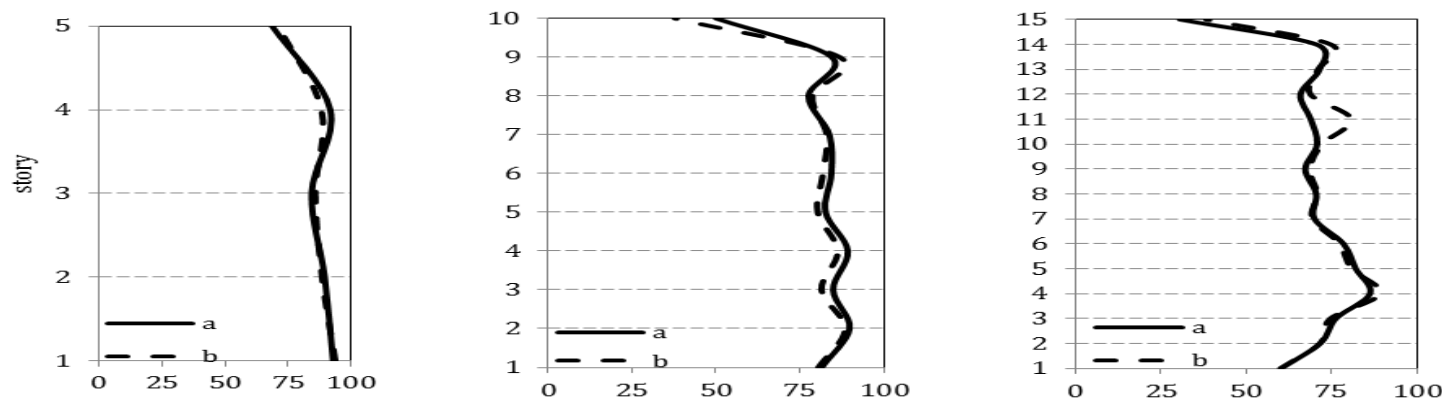

Fig. 14. Share of inverted V bracing system from floor shear in nonlinear static analysis (Shear force of the bracing system to floor shear (\%)).

\section{CONCLUSION}

This study is conducted to investigate the implementation of rule 1-9-4 of the Iranian Seismic Design Code (Standard No. 2800) over dual steel structures by two types of steel braced frame. The effect of this rule was evaluated for resistance of the structure and distribution of lateral load between MRF and bracing system. For this purpose, 5, 10, and 15-floor frames with two types of $\mathrm{X}$ and inverted $\mathrm{V}$ bracing system were modeled and analyzed. The structures were modeled and analyzed in two cases ((a) and (b)) by not following and following the Standard No. 2800. Results of non-linear static analysis showed that the structure capacity in model (b) generally has increased and the model (b) has better a performance level and thus a more desirable nonlinear behavior. The distribution of lateral force between the MRF and the bracing system was different in linear and non-linear static analysis. Furthermore, the distribution of lateral force is changed between MRF and bracing system in model (b). The investigation of plastic hinges formed showed that following the Standard No. 2008 leads to fewer elements entering the inelastic stage. In other words, less plastic hinges are formed in beams and columns and the formation of hinges is observed mostly in the bracing system. 


\section{REFERENCES}

[1] B. Stafford Smith, A. Coull, Tall building structures: analysis and design, Wiley, 1991

[2] A. S. Whittaker, C. M. Uang, V. V. Bertero, An Experimental Study of the Behavior of Dual Steel Systems, University of California, Berkeley, 1990

[3] A. K. Jain, R. G. Redwood, F. Lu, "Seismic response of concentrically braced dual steel frames", Canadian Journal of Civil Engineering, Vol. 20, No. 1, pp. 672-687, 1993

[4] F. A. Charney, V. V. Bertero, An Evaluation of the design and analytical seismic response of a seven-storey reinforced concrete frame-wall structure, University of California, Berkeley, 1982

[5] F. R. Khan, J. A. Sbarounis, "Interaction of shear walls and frames", ASCE. Journal of Structural Division, Vol. 90, No. 3, pp. 10-15, 1964

[6] A. C. Heidebrecht, B. Stafford Smith, "Approximate Analysis of Tall Wall-Frame Structure”, Journal of Structural Division, Vol. 99, No. 2, pp. 1734-1744, 1973

[7] B. S. Smith, M. Kuster, J. C. D. Hoenderkainp, "Generalized method for estimating drift in high-rise structures", Journal of Structural Engineering, Vol. 110, No. 7, pp. 1549-1562, 1984

[8] M. J. Nollet, B. S. Smith, "Stiffened-storey wall-frame tall building structure", Computers \& Structures, Vol. 66, No. 2-3, pp. 225-240, 1998

[9] J. Lee, M. Bang, J. Y. Kim, "An analytical model for high-rise wallframe structures with outriggers", The Structural Design of Tall and Special Building, Vol. 17, No. 4, pp. 839-851, 2008
[10] H. Tekeli, E. Atimtay, M. Turkmen, "A Simplified method for determining sway in reinforced concrete dual buildings and design applications", The Structural Design of Tall and Special Buildings, Vol. 22, No. 15, pp. 1156-1172, 2013

[11] L. J. Aukeman, P. Laursen, "Evaluation of the ASCE7-05 standard for dual systems: response historey analysis of a tall buckling-restrained braced frame dual systems", Structure Congress, pp. 2707-2717, 2011

[12] A. Mehdipanah, S. R. Mirghaderi, S. A. Razavi, "Evaluation of seismic behavior of buckling restrained braced frames as dual system in combination with special moment restring frames", 15th World Conferences on Earthquake Engineering, 2012

[13] A. Mehdipanah, S. R. Mirghaderi, S. A. Razavi, "Seismic performance of stiffness-based designed buckling-restrained braced frame and special moment-resisting frame dual systems", Structure and Infastructure Engineering, Vol. 12, No. 8, pp. 918-935, 2016

[14] American Society of Civil Elilgineers, ASCE7-05, Minimum Design Loads for Building and Other Structures, ASCE, 2005

[15] Permanent Committee of Revising the Code of Practice for Seismic resistant Design of Buildings, Iranian code of practice for seismic resistant design of building (Standard No. 2800), 3rd edition, Building \& Housing Research Center, 2007

[16] American Institute of Steel Construction, Specification for Structural Steel Buildings: Allowable Stress Design and Plastic Design, AISC, 1989

[17] Federal Emergency Management Agency, Prestandard and Commentary for the Seismic Rehabilitation of Buildings, ASCE, 2000 